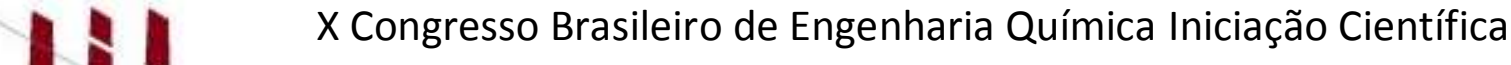 \\ "Influência da pesquisa em Engenharia Química no desenvolvimento tecnológico e industrial brasileiro" \\ Universidade Federal Rural do Rio de Janeiro \\ Universidade Severino Sombra \\ Vassouras - RJ-Brasil
}

\section{INFLUÊNCIA DAS CONDIÇÕES DE SECAGEM DAS FOLHAS DE OLIVEIRA NO CONTEÚDO DE CAROTENOIDES}

\author{
L. M. M. MACHADO*1, G. S.ROSA ${ }^{2}$ \\ ${ }^{1}$ Acadêmica da EQ/UNIPAMPA ${ }^{2}$ Docente da EQ/UNIPAMPA \\ Engenharia Química - Universidade Federal do Pampa \\ Travessa 24, $n^{\circ}$ 1650, Bairro Malafaia, CEP. 96.413-170, RS, \\ E-mail: gabrielarosa@unipampa.edu.br
}

\begin{abstract}
RESUMO - As folhas de oliveira têm sido alvo de diversos estudos, tendo como descoberta vários benefícios à saúde. Entre os compostos bioativos presentes nas folhas de oliveira têm-se os carotenoides, um grupo de pigmentos, que são responsáveis pelas cores vermelha, laranja e amarela. Este trabalho teve como objetivo estudar a secagem das folhas de oliveira e verificar a influência deste processo no conteúdo de carotenoides. $\mathrm{O}$ equipamento utilizado para os ensaios de secagem foi um secador de leito fixo com passagem paralela de ar, nas temperaturas de 50 e $70^{\circ} \mathrm{C}$ e velocidade do ar de $2 \mathrm{~m} / \mathrm{s}$. A determinação dos carotenoides totais foi realizada através da metodologia deRodriguez-Amaya (1999). Através dos resultados verificou-se que o aumento da temperatura proporcionou a aceleração do processo, o que reduziu o tempo de secagem. Para a secagem realizada na temperatura de $50{ }^{\circ} \mathrm{C}$ a cinética apresentou somente um período de taxa decrescente, enquanto que para a temperatura de $70{ }^{\circ} \mathrm{C}$ foi possível observar um período de taxa constante no início do experimento. Com relação ao conteúdo de carotenoides, observou-se que a amostra seca em maior temperatura teve maior perda deste composto.
\end{abstract}

Palavras chave: secador, pigmentos, bioativos.

\section{INTRODUÇÃO}

A oliveira Olea europaea L., da famíliaOleaceae,é uma árvore de tamanho médio, cujo porte, densidade da copa e cor da madeira variam em função da variedade e de condições de cultivo. A coloração do fruto varia do verde aos tons acinzentados, dourado, castanho-claro, roxo ou preto, quanto mais escuro maior o tempo de maturação do fruto, sendo que cerca de $25 \%$ de sua composição é o azeite de oliveira(OLIVEIRA et al., 2003).
As folhas de oliveira têm sido utilizadas para formulação de medicamentos, sendo ricas em compostosnutricionais e medicinais. Um dos inúmeros compostos bioativos presentes na folha de oliveira são os carotenoides, que são pigmentos naturais que vão do amarelo até vermelho intenso, coloração característica presente em frutos, vegetais, dentre outros alimentos. Os carotenoides possuem também atividades antioxidantes, devido sua interação com radicais livres, agindo assim na prevenção 
de doenças cancerígenas até doenças cardiovasculares (SOUZA et al., 2011).

A secagem está entre as operações unitárias mais usuais na indústria química, utilizada para que não ocorra a degradação do material, permitindo um tempo maior de conservação (PACHECO, 2009).

Em face disto, este trabalho teve como objetivoestudar a secagem de folhas de oliveira e verificar a influência deste processo no conteúdo de carotenoides.

\section{MATERIAS E MÉTODOS}

\section{Matéria Prima}

A presente pesquisa foi realizada no Laboratório de Fenômenos de Transportes da Universidade Federal do Pampa. Foi utilizada como matéria prima as folhas de oliveira, cedidas por produtores do município da região do Pampa Gaúcho. As amostras foram colhidas no período da manhã e armazenadas sob refrigeração. A análise de umidade da matéria prima foi realizada pelo método de secagem em estufa a $105^{\circ} \mathrm{C}$ por $24 \mathrm{~h}$.

\section{EquipamentoExperimental}

Para realização dos experimentos de secagem da folha da oliveira utilizou-se um secador de leito fixo de fluxo paralelo, conforme mostra a Figura 1.

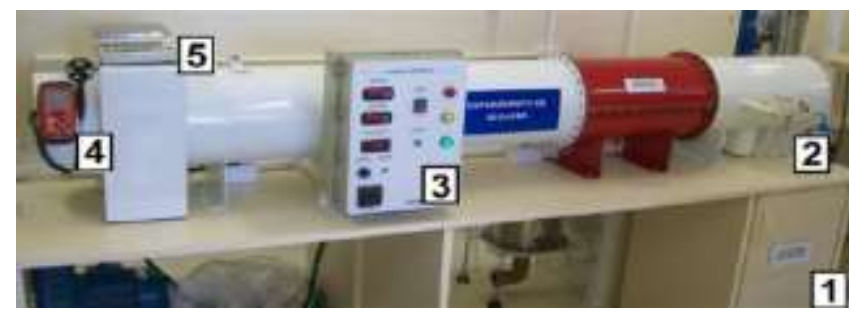

Figura 1 - Secador de leito fixo.

O equipamento utilizado foi um secador composto por (1) soprador centrífugo, (2) psicrômetro, (3) painel elétrico que controla a temperatura do ar de secagem e as temperaturas de bulbo seco e bulbo úmido do ar, (4) anemômetro que verifica a velocidade do ar de secagem, e no interior do túnel uma bandeja que se encontra acopladana balança eletrônica (5) que realiza determinação das massas das amostras.
Para a realização das análises de carotenoides foi utilizado o espectrofotômetro, conforme a Figura 2.

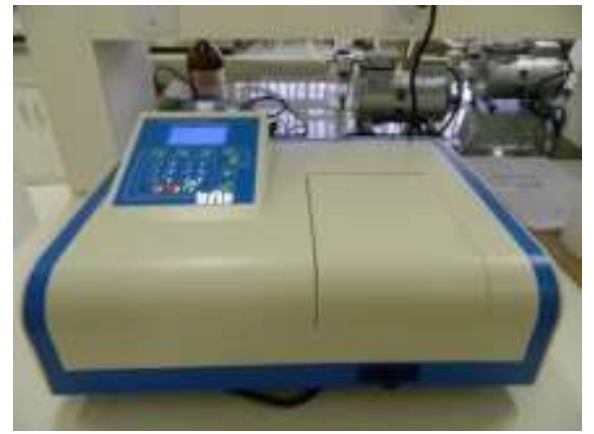

Figura 2 - Espectrofotômetro.

\section{Procedimento experimental}

Para realização dos ensaios de secagem, verificou-se se o psicrômetro estava preenchido com água. O soprador foi ligado, ajustando a velocidade do ar de secagem requerida. Após atingir as condições de regime permanente, a bandeja com amostras foi inserida no interior do secador, registrando o peso inicial do conjunto. Foram monitoradas durante o experimento as condições massa da amostra, temperatura do bulbo seco e bulbo úmido com auxílio do psicrômetro, e a temperatura do ar de secagem. Nos primeiros 75 min de secagem foram monitoradas essas condições a cada 2 min e $3 \mathrm{~min}$, após a cada 5 min até massa constante, assim sendo finalizado o processo de secagem.

Para determinação de carotenoides totais presentes na folha de oliveira utilizou-se a metodologia de Rodriguez-Amaya (1999). Foram pesadas $2 \mathrm{~g}$ de amostra previamente moída e $2 \mathrm{~g}$ de celite. Adicionou-se $20 \mathrm{~mL}$ de acetona gelada, agitando-se o conteúdo por 10 min. para homogeneização. O conteúdo foi filtrado em funil de buchner com papel filtro, durante a filtragem lavou-se a amostra com $250 \mathrm{~mL}$ de acetona gelada até que o extrato ficasse incolor. $\mathrm{O}$ filtrado foi transferido para funil de separação, onde acrescentou-se $20 \mathrm{~mL}$ de éter de petróleo e $25 \mathrm{~mL}$ de água destilada. Descartou-se a fase inferior e repetiu-se o procedimento por 4 vezes para ocorrera remoção total de acetona. Transferiu-se o extrato superior para um balão volumétrico de $50 \mathrm{~mL}$, completando-se o volume com éter de petróleo. Após efetuou-se a leitura em espectrofotômetro em comprimento de onda 
de $450 \mathrm{~nm}$, usando como branco éter de petróleo.

Para o cálculo da determinação do conteúdo de carotenoides utilizou-se a Equação 1.

$$
\operatorname{Carot} .\left(\frac{m g}{100 g}\right)=\frac{D O \cdot 50 \cdot 1000000}{2500.100 . m}
$$

em que $D O$ é absorbância em é a massa de amostra.

\section{RESULTADOS E DISCUSSÃO}

As folhas de oliveira in naturacaracterizaram-se por apresentar conteúdo de umidade de 50,96 $\pm 0,02 \%$ (b.u). As curvas de cinética de secagem das folhas de oliveira secas em leito fixo foram construídas a partir do conteúdo de umidade (b.s) em função do tempo. Os resultados das curvas de secagem encontram-se na Figura 3, em que as temperaturas das secagens foram 50 e $70^{\circ} \mathrm{C}$ e velocidade do ar $2 \mathrm{~m} / \mathrm{s}$.

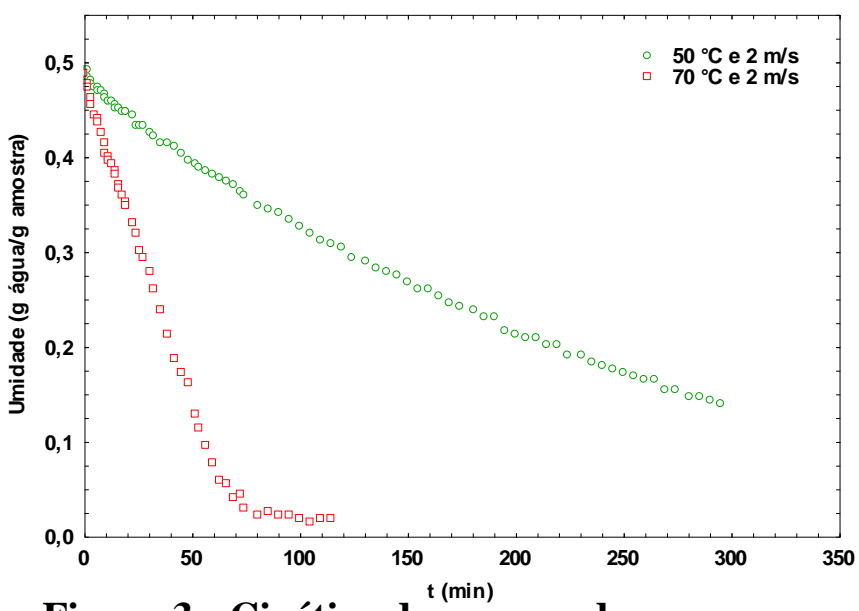

Figura 3 - Cinética das curvas de secagem em diferentes condições.

Na Figura 3 pode-se verificar que com o aumento da temperatura do ar ocorreu aceleração do processo de secagem,proporcionando um tempo mais curto de processo.O conteúdo de umidade das amostras após as secagens foram de 1,9 e 13,9 $\%$ (b.u.) para 50 e $70{ }^{\circ} \mathrm{C}$, respectivamente. Para a secagem realizada na temperatura de 50 ${ }^{\circ} \mathrm{C}$ a cinética apresentou somente um período de taxa decrescente, enquanto que para a temperatura de $70{ }^{\circ} \mathrm{C}$ foi possível observar um período de taxa constante no início do experimento. De acordo com Mujumdar (2006) durante o período de secagem em taxa decrescente, os fatores que influenciam o processo são função da natureza física do produto, a temperatura, e o seu teor de umidade.

Na Tabela 1 apresentam-se os resultados do conteúdo de carotenoides totais das amostras in natura e secas.

Tabela 1 -Análise de carotenoides totais das amostras in natura e secas.

\begin{tabular}{cc}
\hline Amostras & $\begin{array}{c}\text { Carotenoides totais } \\
\text { (mg carotenoides } / 100 \mathrm{~g} \text { s.s..) }\end{array}$ \\
\hline in natura & $109,3 \pm 3,9$ \\
$50^{\circ} \mathrm{C}$ & $108,6 \pm 2,7$ \\
$70^{\circ} \mathrm{C}$ & $84,1 \pm 2,5$ \\
\hline
\end{tabular}

Não foi observada diferença significativa entre os carotenoides presentes na amostra in natura e na amostra seca em $50{ }^{\circ} \mathrm{C}$, o que indica que esta temperatura não proporcionou a perda destes biocompostos. Entretanto, o mesmo não foi observado para a amostra seca em $70{ }^{\circ} \mathrm{C}$, em que perdeu-se cerca de $23 \%$ dos carotenoides. As folhas in natura apresentaram $52,08 \mathrm{mg} / 100 \mathrm{~g}$ (b.u.) de carotenoides, sendo este conteúdo superior ao reportado por Bauer et al. (2011) para os frutos de azeitona $(2,15$ $\mathrm{mg} / 100 \mathrm{~g}$ )

\section{CONCLUSÃO}

As folhas de oliveira in natura caracterizaram-se por apresentar conteúdo de umidade de 50,96 \% (b.u). As curvas de secagens apresentaram período de taxa decrescente para $50{ }^{\circ} \mathrm{C}$ e constante seguido de decrescente para $70{ }^{\circ} \mathrm{C}$.Através da pesquisa verificou-se a influência da temperatura de secagem sobre o conteúdo de compostos bioativos (carotenoides) presentes na folha da oliveira, de forma que para a maior temperatura observou-se uma maior perda no conteúdo de carotenoides. 


\section{REFERÊNCIAS}

BAUER, V. R. P.; DUTRA. F. L. G.; ZAMBIAZI, R. Caracterização do fruto da Oliveira na região Sul do Brasil. Alim. Nutr., Araraquara, v. 22, n. 1, p. 79-87, jan./mar., 2011.

MUJUMDAR, A. S. Handbook of industrial drying. Taylor and Francis Group, 3 ed., 2006.

OLIVEIRA, A. F.; PASQUAL, M.; CHALFUN, N. N. J.; REGINA, M de A.; RINCÓN, C. D. R. Influência do número de nós em estacas semilenhosas de Oliveira (Olea europaea L.) no enraizamento sob câmara de nebulização. Ciênc. Agrotec. Lavras. v.27, n.2, p.332338, mar./abr., 2003.

PACHECO, C. R. F. Conceitos básicos de Secagem. Curso de Especialização de Papel e Celulose, 2009.

RODRIGUEZ-AMAYA, D. B. A Guide to Carotenoid Analysis in Foods. Washington DC: International Life Sciences Institute (ILSI) Press, 1999.

SOUZA, C. O.; MENEZES. J. D. S.; NETO. D. C. R.; ASSIS. J. G. A.; SILVA, S. R.; DRUZIAN, J. I. Carotenoides totais e vitamina A de cucurbitáceas do Banco Ativo de Germoplasma da Embrapa Semiárido. Ciência Rural, Santa Maria,2011.

\section{AGRADECIMENTOS}

A Universidade Federal do Pampa e Pró-Reitoria de Assuntos Estudantis e Comunitários (PRAEC) pelo auxílio cedido para participação do evento. 